\title{
A.JO'ГE
}

African Journal of Teacher Education

ISSN 1916-7822. A Journal of Spread Corporation

Vol. $7 \quad$ No. $2 \quad 2018 \quad$ pp. $17-37$

\section{Language Anxiety and Achievement among Freshman Students of Addis Ababa University, Ethiopia}

\author{
Bekau Atnafu Taye \\ Kotebe Metropolitan University, \\ Addis Ababa, Ethiopia
}

\begin{abstract}
The objectives of this study are to measure levels of students' anxiety and to see whether anxiety affects their academic performance. The participants of the study were drawn from the Department of Foreign Languages and Literature at Addis Ababa University (AAU). The study used primary and secondary data and descriptive and inferential statistics. The inferential statistics was made in terms of one-way ANOVA. The results of the study showed that first year students were anxious, and the level of anxiety affected their performance. It was also found that anxiety and achievement have curvilinear relationships. Ameliorating strategies implied from the findings were also suggested.
\end{abstract}

Key words: achievement, anxiety, language

\section{Theoretical Basis of the Study}

Psychologists have defined anxiety as a general term referring to the feeling of nervousness, fear, apprehension and worrying. Psychologists (Comer, 2007; Dworetzky, 1988; Myers, 2007) viewed anxiety as a disorder that they classified into various types including, generalized anxiety disorder, panic disorder, phobic disorder, obsessive-compulsive disorder, post-traumatic disorder, social anxiety and separation anxiety. Anxiety is a complex phenomenon involving a blend of bodily and mental changes that include the following pieces: arousal, feeling, thoughts and actions, together. Thus, experiencing emotion in general or anxiety in particular is a joint effect of physiological arousal and cognitive appraisals. 
In the realm of language learning too, scholars such as Horwitz et al., (1986) defined anxiety as the subjective feeling of tension, apprehension, worries and nervousness associated with an arousal of the autonomic nervous system. Communication apprehension, test anxiety and fear of negative evaluation provide useful conceptual building blocks for a description of Foreign Language Anxiety (FLA) apart from perceiving FLA as a distinct complex of self-perceptions, beliefs, feelings, and behaviors related to classroom language learning (Horwitz et al., 1991). Communication apprehension is a type of shyness or difficulty in speaking in public characterized by fear about communicating with people. Test anxiety is a type of performance anxiety caused by fear of failure. Fear of negative evaluation is apprehension about others' evaluations; it is avoidance of evaluative situations. It is the act of trying to avoid the feared object or situation at all costs because there is an intense and excessive fear of being observed or evaluated by others. As a result, a mere dislike of interaction or class discussion might happen. For MacIntyre and Gardner (1991) communication anxiety is related to social evaluative anxiety as each involves apprehension surrounding social perceptions and self-consciousness when speaking or participating in a social context. For Horwitz et al., the essence of communication anxiety is limited to classroom situation whereas for MacIntyre and Gardner, communication anxiety refers to a broader context. Contrary to Horwitz et al, (1991), MacIntyre and Gardner (1991) suggest that test anxiety is also a general problem and not one specific to the language classroom. That is, test anxiety is prevalent in all subjects; students are anxious while taking any kind of tests. Test anxiety is not a peculiar characteristic of language learning.

Scovel (1978) cited in Young (1991) concluded that research, dealing with the relationship of anxiety to foreign language learning, provided mixed and confusing results and that anxiety is neither a simple nor will-understood psychological construct. However, since the mid-1980, most researchers have adopted a situation-specific approach to foreign language anxiety and conceptualized it as a distinct form of anxiety expressed in response to second or foreign language learning rather than a manifestation of other more general types of anxiety (Cheng, 2001). Due to this, anxiety is explained as the subjective feeling of tension, apprehension, worry and nervousness associated with an arousal of the autonomic nervous system (Horwitz et al., 1986) caused by situational variables. 
Language anxiety is not exclusive to beginners; university students with an extensive language learning background can also perceive considerable levels of language anxiety (Ortega-Cebreros, 2003). There are apparent reasons on the part of language students to experience anxiety. Language learners have the dual task, not only of learning a second language but also performing in it (Foss \& Reilzel, 1991); as a result, language anxiety is more likely to occur in foreign language lessons than in lessons in the other subjects of the curriculum (Ortega-Cebreros, 2003). This course of event seems natural since in addition to all the usual concerns about oral communication, the foreign language class requires students to communicate via a medium in which only limited facility is possessed (Horwitz et al., 1991). These additional feelings of incompetence about grasping the language in the first place and about the inability to present oneself in a way consistent with one's self-image would induce anxiety (Foss \& Feilzel, 1991). Thus, the uniqueness of foreign language anxiety in comparison with other academic anxieties lies on the interactive nature of language classrooms and the continual request on learners to communicate (Ortega-Cebreros, 2003). Furthermore, students are requested to communicate by means of an instrument with which they are not adequately familiar. For most students delivering a speech in front of others is likely to induce some degree of anxiety. A milder degree of anxiety might be functional but if the level of anxiety interferes with the person's normal functioning, it affects the process of communication in a serious way.

The language learning field also classifies anxiety as trait, situation-specific and state anxiety. Trait anxiety refers to a stable predisposition to become nervous in a wide range of situations and there is always a probability of being anxious in any situation (MacIntyre, 1999; Young, 1991). Young (1999) kept saying that people with high levels of trait anxiety are generally nervous people; they lack emotional stability. In other words, trait anxiety is a feature of an individual's personality. Here, anxiety is more than an occasional experience. It is part of the individual's psychological makeup and such people are anxious and they worry about little things. This type of anxiety is viewed at the deepest or global level because anxiety is experienced as a permanent trait as some people are predisposed to be anxious (Brown, 1994). Regardless of the situation people are in, there are some who often experience anxiety. Anxiety in this case is the unique personality of those individuals. In general, such people are prone to experience anxiety. 
At a more local or situational level, anxiety can be experienced in response to a particular situation or act (Brown, 1994). Anxiety caused by language learning is a specific anxiety rather than a trait anxiety. On the other hand, situation-specific anxiety which is stable over time but not necessarily consistent across situations applies to a single context or situation (MacIntyre, 1999). Math anxiety, test anxiety, language anxiety, stage fright are examples mentioned under situation-specific anxiety. Under such type, anxiety is transient and it becomes temporary; it comes and goes.

State anxiety, on the other hand, refers to the moment-to-moment experience of anxiety; it is the transient emotional state of feeling nervous that can fluctuate over time and vary intensity (MacIntyre, 1999). MacIntyre further noted that applied to language learning, we can see that person with a high level of language anxiety will experience state anxiety frequently.

In terms of occurrence, state anxiety is the first phase of situation-specific anxiety. That is, situation specific anxiety comes to exist after state anxiety laid its own foundation. In relation to this, MacIntyre (1999) indicated that if a student becomes anxious in learning grammar, comprehension and speaking in the earlier stages of language learning, or if he /she feels uncomfortable making mistakes, the state anxiety occurs. After experiencing repeated occurrence of state anxiety, the student comes to associate anxiety arousal with the second/ foreign language and when this happens, the student expects to be anxious in second language contexts (Ibid).

In other words, language anxiety is conceptualized by many language anxiety researchers (Kondo \& Ying-Ling, 2004) as a situation-specific personality trait. Unlike generalized anxiety disorder, language anxiety is not a free-floating anxiety in which a person cannot relate the feelings of anxiety to one specific thing. Comparison between state and traits anxiety revealed that it is state anxiety that influences the language learning process (Ellis, 1994; Feigenbaum, 2007). This specific anxiety, which has been responsible for students' uncomfortable experiences in language classes, was proposed (by Horwitz, Horwitz \& Cope, 1986) to be called Foreign Language Anxiety (Horwitz, 2001). According to Horwitz, Horwitz and Cope (1986), this anxiety stems from the inherent inauthenticity associated with immature second/foreign language communicative ability (Horwitz, 2001). Anxiety is a common experience for the majority of the students. It is more of a natural reaction to a novel situation. However, anxious students are said to differ from others due to the excessive and intense fear of every classroom interaction, actions 
and being worried about every classroom event. Their serious emotional disturbance violates the accepted expectations of classroom interaction.

To sum, from a theoretical perspective, language anxiety is a form of situation-specific anxiety (MacIntyre, 1999) existing in foreign language classes. It is the peculiar features of the language classes and it is different from the other forms of anxiety such as trait anxiety, audience anxiety, communication apprehension, interpersonal anxiety, novelty anxiety and math anxiety. For example, a person who experienced a considerable amount of language anxiety might not feel at all nervous about learning math. Language anxiety, thus, is a situation-specific form of anxiety that does not appear to bear a strong relation to other forms of anxiety.

In other words, language anxiety is caused by situational factors, implying that it is the learning environment that triggers anxiety on students. Learning environment includes the teacher, students and the material to be learnt and the activities given. For Finch (2001) learning environment is all personal histories, values, assumptions, beliefs, rights, duties, obligations and learning styles, fostered by a climate of cooperative social interaction that would be considered as aspects of learning environment. For Finch, learning environment embodies not only the social aspect of the learning but also the psychological components since assumptions, values, and beliefs are more of psychological constructs.

Within the domain of language learning, many studies have investigated the effect of the learning environment. Finch (2001), for example, stated that creative production is possible only in a non-threatening environment which encourages meaningful learning and the creative use of English. Gebeyehu (2005) stated that a relaxed classroom atmosphere is significant in reducing anxiety. An understanding of the ways in which aspects of the environment affect learning is particularly important for language teachers and learners (Williams \& Burden, 1997). It is obvious that a low-stress language learning environment must be an important aspect of the teaching process. Conducive learning environment has enormous potential to improve the success of language acquisition.

When students encounter a new learning environment, they need to cope with new interpersonal relationship. Building new relationship with roommates and teachers may threaten one's affective factors if the environment is not modified as per the needs of the students. Due to this, teachers are supposed to create a non-threatening learning environment. 


\section{Statement of the problem}

The universities in Ethiopia, as elsewhere, enroll students from different backgrounds with different needs, beliefs, expectations, desires, wants, learning styles and personality types. Interactions among these multiple agenda affect the teaching learning process. In the process of adjustment, students are trying to form harmonious relationship between their individual needs and the new environment in which they belong. Many students enter higher education with only vague ideas about specific aspects of the experience which lies ahead (James, 2001). One-third of first year school-leavers in Australia believe that they were not ready to choose a university course during their final year of school (James \& Hartly, 2000 cited in James, 2001). Similarly, James (2001) citing Yorke (1999, 2000) identified 'wrong choice of programme' as the first among seven key factors in undergraduate non-completion in the United Kingdom. In the USA, Wiese (1994) cited in James (2001) has described the cognitive dissonance that occurs for first year students of this kind when experiences contradict built-up expectations. In the Ethiopian context, too, Yalew's (2003) findings portrayed that the rates of attrition were high in the first year of university education and declined considerably thereafter. The consequences of this situation are highly speculative, but it is possible that universities are missing the opportunities to 'capture' student engagement during the early formative weeks (James, 2001). This implied that students entering higher learning institutions have had various psychological and social problems that could limit the development of their potential.

These students, first year Ethiopian university students, exhibited low performance in language classes (Bekalu, 2006; Mekonnen, 1998; Solomon, 2001). The causes for their poor performance could be multi-dimensional, though, researchers explained the reasons in terms of insufficient coverage of communicative skills in the courses (Mekonnen, 1998; Solomon, 2001), new education system (Seleshi, 2001; Seyoum, 1996).

Understanding these problems of the students is less of an option and more of a necessity. As a result, investigating the students' psychological conditions is found to be important. Because learning may not become a priority when there are other immediate psychological concerns. Thus, this study examines one of the psychological factors-anxiety in the foreign language classes. In addition to this, it tries to determine the effects of anxiety on students' performance. Having said this, this study tries to answer the following research questions: 
1. What is the level of anxiety that freshman students experience in foreign language classes?

2. Is there performance difference between students who have different levels of anxiety?

\section{Method}

\section{Participants and Procedures}

The target population for this study was first year students in the Department of Foreign Languages and Literature (students majoring in Foreign Languages and Literature), at Addis Ababa University (AAU) in 2016. According to the survey made by the researcher, there were three hundred first year students majoring in Foreign Languages and Literature at AAU.

In the first semester of the year, students took six courses: Communicative English I, Reading Skills, Fundamentals of Literature, Introduction to Language and Literature, Logic, and Civic and Ethical Education. From these, language courses were identified since it was assumed that language courses were those that trigger anxiety in students. These courses required students to speak and listen with a reasonable degree of fluency and accuracy, write well developed paragraphs, read various materials and make their own notes, apply different skills and strategies in their speech and writing. As it was observed from the course outline, instructors are supposed to use gapped-lecture, pair and group work, role playing, presentation, individual work and whole class discussion. These activities, which are basic features of language classes, might cause anxiety; hence, this study was conducted considering the language courses the students took

The target population was surveyed in the first semester of the year after three months classroom instruction. It was believed that students who were exposed to three months of contact can offer meaningful commentary about their language learning experience (Campbell, 1999). Campbell (1999), on the other hand, considering fourteen days of classroom instruction (two weeks after classes began) sufficient, conducted his survey to gather meaningful experience about the nature of students' language learning. This study was conducted in a similar vein. A volunteer sample of AAU freshman students was solicited to participate in the study. Freshman students in the Department of Foreign Languages and Literature were classified into nine groups or classes. Of all the classes, eight groups or classes were considered for the questionnaire survey. One group was intentionally excluded from the study because it was taught by the 
researcher. Those students who were willing to fill in the questionnaire were chosen. Three hundred copies of the questionnaires were distributed to the students while students were in the classroom. In the process, an attempt was made to make students give their responses without consulting with their friends. In administering the quantitative tools, throughout the procedure, students were allowed to ask for clarifications on any issue they did not fully understand. Students were asked to write their ID numbers while they filled out the questionnaire. Out of three hundred students, eighty-two students volunteered their ID numbers. The CGPA of these eight two students was obtained from the Office of the Registrar and the analysis was made. It was only the cumulative GPA of the students in language courses which were considered during the analysis.

\section{Instruments}

Anxiety is usually measured in one of three ways: by behavioral tests, where the actions of a subject are observed; by the subject's self-report of internal feelings and reactions, or by physiological tests that measure heart rate, blood pressure etc. The second method was the most common used in measuring anxiety-self-reports (Daly, 1991; Scovel, 1991). Consequently, the level of language anxiety university students experience was measured by Foreign Language Classroom Anxiety Scale (FLCAS) instrument, which measures the degree to which an individual feels anxious in language classes. This instrument has been used in many studies of anxiety in foreign language learning and found to be a highly reliable and valid measure (Aida, 1994; Sparks \& Ganschow, 1999; Maclntyre \& Gardner, 1999; Price, 1991). The instrument was used to assess the level of anxiety students experience and to determine whether the level of anxiety has an effect on their achievement.

Each item contains five-point Likert-format choices in which, 5=strongly agree, 4=agree, $3=$ neutral, $2=$ disagree, $1=$ strongly disagree. Of all the thirteen-three items, ten items were positively worded and the remaining items are negatively worded. All positively worded items were reversed before the analysis. Thus, in all items high scores represent high levels of anxiety. Based on the answers in the anxiety measure questionnaire, students were classified into three anxiety groups: low, medium and high. 
For their academic performance, the first semester of 2016 CGPA was used. The students' CGPA was secured from the Office of the Registrar. Thus, each student's numeric grade of anxiety level was evaluated against the CGPA of the first semester.

The results of the study were tabulated and analyzed by using descriptive and inferential statistical values. The descriptive statistics was used to classify and summarize numerical data using mean, minimum, maximum, percentage and the like. In short, the descriptive data analysis was used as a gate valve for the inferential statistics. The inferential statistics was made in terms of one-way ANOVA. One-way ANOVA indicated the degree of the effect that the independent variable (anxiety) has on achievement. Furthermore, inferential statistics was computed to determine whether or not the results that were obtained in the sample were powerful enough to generalize to the whole population. This was made because the descriptive statistics did not allow drawing any general conclusion that would go beyond the sample. Thus, to venture any generalization concerning the wider population and not just the particular sample, the researcher conducted one-way ANOVA.

For multiple comparisons among means of the levels of the independent variable (anxiety), Tukey test or Honestly Significant Difference (HSD) test was used.

\section{Results of the Study}

Table I: Descriptive Statistics about the levels of anxiety

\begin{tabular}{|l|l|l|l|l|l|l|}
\hline Anxiety Level & $\mathrm{N}$ & Min. & Max & Mean & St.D. & Percent \\
\hline Low & 20 & 71 & 95 & 84.0 & 7.5 & 24.4 \\
\hline Medium & 41 & 96 & 112 & 103.0 & 4.6 & 50.0 \\
\hline High & 21 & 113 & 147 & 123.0 & 10.8 & 25.6 \\
\hline
\end{tabular}

The possible scores on the foreign language classroom anxiety scale range from 33 to 165 . In the present study, as per the data above, scores ranged from 71 to 147 . This implies that the majority of the participants seemed to be anxious. In addition to this, a point worthy of noting in this table is the degree of dispersion. The standard deviation for the third group (high anxiety score) is 10.8 which is the largest standard deviation from the group. This indicates that students' score on anxiety is spread out. On the other hand, although half of the target population is under the 
second group (medium), the scores tend to cluster, and the degree of dispersion appears to be homogeneous.

The means of the levels of anxiety were 84.0, 103.0 and 123.0. To see whether there is significant variation among these means, analysis of variance was made (see table II).

Table II: Analysis of Variance showing Performance Difference of Students who have various degree of anxiety

\begin{tabular}{|l|l|l|l|l|l|}
\hline Source of Variation & SS & DF & MS & F & P \\
\hline Between groups & 10.489 & 2 & 5.244 & 23.607 & .000 \\
\hline Within groups & 17.550 & 79 & .222 & & \\
\hline
\end{tabular}

The table above shows the overall difference among the groups. This indicates that there is statistically significant difference between the comparison groups, implying that CGPA scores differ among groups over high, medium and low categories $(\mathrm{F}=23.607, \mathrm{P}<0.05)$. In addition to this, it is necessary to test each of the level of anxiety to know the relative contribution of each level to the achievement score. For this, the table below is prepared.

Table III: ANOVA table for Multiple Comparisons among the levels of the Independent variable (anxiety) on achievement

\begin{tabular}{|c|c|c|c|}
\hline Anxiety Level & Mean Difference & Std. Error & Sig. \\
\hline 1 & $.68946^{*}$ & .12855 & .000 \\
\hline 2 & $.97562^{*}$ & .14726 & .000 \\
\hline 3 & .28616 & .12648 & .067 \\
\hline
\end{tabular}

Note: $1=$ low anxiety score $3=$ high anxiety score $2=$ medium anxiety score

From the table above, the mean difference between low and medium anxiety scores is 0.68946 and this difference was found to be statistically significant at 0.05 level. In the same manner, the mean difference between low and high anxiety scores is 0.97562 and this difference was also found to be statistically significant at 0.05 level. However, there is no statistically significant difference between medium anxiety score and high anxiety score. 


\section{Discussion}

A significant percentage of research in learning to date has focused on the cognitive domain and its role, missing the role of the affective factors. In this regard, Young (1999) stated that the emotional part of learning was virtually ignored for so long. Latterly though, research in the area of affect has begun to emerge. It has become clear that affect is a key stone of teaching. Teaching is not only a cognitive-based unitary faculty; rather it encompasses affective factors. Owing to this, affect is becoming known and it sails researchers deep into its effects. As a result, emotion in general and anxiety in particular have emerged as a legitimate area of research. A lack of sensitivity by teachers to students' emotional demand creates conditions for the growth of student anxiety. In the present study, it was found that freshman language students were anxious. Many of the students endorsed statement like:

I never feel quite sure of myself when I am speaking in my foreign language class. $(45.9 \%)$

I tremble when I know that I am going to be called on in language class. (32.6\%)

It frightens me when I do not understand what the teacher is saying in the foreign language class. $(46.6 \%)$

It would bother me to take more foreign language class. (52.6\%)

These sample statements showed that a significant number of students were found to be anxious. In view of the above, it seems safe to say that freshman foreign language students became anxious in foreign language classes. This finding was consistent with the results of other studies done in the area (Abate, 1996; Gebeyehu, 2005; Leki, 1999; Phillips, 1999; Young, 1999).

The effect of anxiety is highly marked in the foreign language classes. In language classes, students have dual tasks, grasping a language item and practicing it. Practicing the language item in front of the classroom invites emotional instability. The problem is more pronounced because of the inadequate language skills students have been equipped with. Regarding the background of the students, researchers (Bekele, 2007; Berhanu, 2000; Tamene, 2000) noted that students have had poor academic background when joining higher learning institutions. This poor academic background compounded by anxiety drag the performance of the students out the right direction. 
While there is less basic agreement about the relationship between anxiety and achievement at a general level, the results of the present study, nonetheless, support the premise that anxiety brings effects on the academic achievement of the students. That is, students with high language anxiety obtain significantly low grades in foreign language classes. Here, anxiety contributes to performance. A growing body of research indicates this fact. For example, Gardner et al.,(1976) cited in MacIntyre (1995) found out that as the grade level increased from grade seven to grade eleven, language anxiety became a better predictor of achievement in second language course. This happens because when individuals move from childhood to adolescence or to adulthood, they start forming their own individual identity and becomes sensitive not to be mocked or ridiculed while making mistakes.

Contrary to this, Sparks and Ganschow (1999) have relegated language anxiety to the status of an unfortunate side effect and those students' overall language skills are rather likely to affect their levels of anxiety about language learning. For them, language anxiety results from failure and does not cause it. Sparks and Ganschow underestimate the role of anxiety on achievement; they move a further length to argue that failure does not relate to emotional elements. This assertion seems to be far from a stock of similar findings, asserting that the role of emotion on performance is beyond debate. MacIntyre (1995) contradicts this claim and stated that language anxiety is a cause of problems in language learning rather than a consequence. For MacIntyre, when anxiety is high, cognitive performance is diminished because of the divided attention and therefore performance suffers. Young (1999), on his part, noted that cognitive processing is short-circuited by emotions, which trigger a complete synchronization of the brain's resources. That is, when a person becomes anxious, the full capacity of the individual's mental resources could not be utilized. Only leftover cognitive resources are being used. While apprehensive, self-sabotaging thoughts intrude on the minds of the learners and affect the movement of information. That is, the transformation of information from short term to long term memory and vice versa could be hampered by anxiety.

Considering the above, the present researcher takes a compromise position and claims that anxiety is both, a cause and a consequence. A more extensive follow-up study (Bekalu, 2010) found out that anxiety is caused by poor academic background. That is, students who are poor in basic linguistic skills are likely to experience anxiety in foreign language classes. Thus, in this case, anxiety becomes a consequence. In the present study, it was found out that anxiety 
impairs performance, being a cause. Thus, it is possible to draw conclusion that anxiety is both a cause and a consequence. Furthermore, in the area of affective factors, researchers also claimed that anxiety has relationship with academic achievement (Abate, 1996; Campbell, 1999; Gebeyehu, 2005; MacIntyre \& Gardner, 1991; Young, 1991).

In addition to this, anxiety increases the likelihood for disengagement. Students with high language anxiety tend to avoid practicing language skills. This is because highly anxious students appear to use avoidance of tasks as one of the coping strategies; they are not willing to communicate. This strategy retards the development of language acquisition because absence of practice influences skill development. In line with this, Young (1991) stated that anxiety may affect the quality of an individual's communication or willingness to communicate.

To make the discussion clear, let us see the following lucid description of the graph, showing the relationship between anxiety and achievement. The interaction between the effects of anxiety and achievement is in a form of a curvilinear relationship.

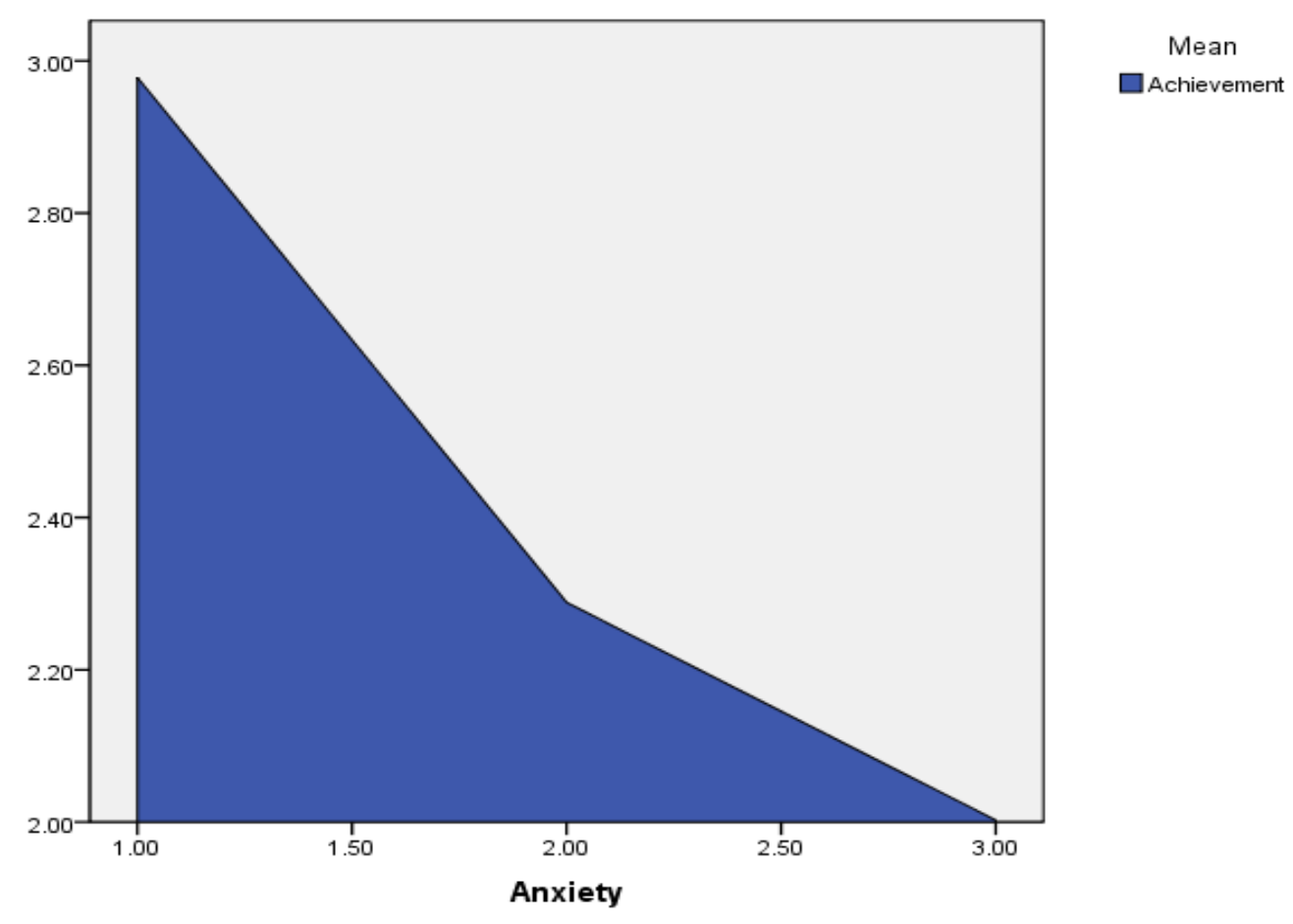

Fig.1 The relationship between anxiety and achievement

The graph above generates two sets of findings. The first discussion rests on the positive effect of anxiety. When anxiety is less, performance goes up. Here, anxiety is a motivational tool and it tends to facilitate the process of learning. A certain amount of anxiety provides the optimal 
conditions for highest academic performance and it makes students appear to be more emotionally competent. Better emotional understanding cultivates cognitive resources; as a result, performance increases.

The second point of discussion suggested from the graph refers to the negative effect of anxiety. As observed from the graph, when the level of anxiety increases, performance decreases; in this case, anxiety adversely affects academic performance because the full extent of an individual's capacity cannot be employed. MacIntyre and Gardner (1991) noted that the subjects with high anxiety would perform poorly on all three tasks-oral, written and recall. The model to be suggested is that foreign language anxiety causes poor performance in the foreign language that produces elevations in state anxiety. Similarly, Campbell (1999) noted that all researchers in the area of anxiety agree that the nature of anxiety in question is debilitating, not facilitating; that is, it impedes rather than enhances learning. In general, the activities in the foreign language class that create an atmosphere of panic, fear, anger, and unpleasant feelings which are psychologically and physiologically associated with anxiety can impede language acquisition (Koch \& Terrell, 1991).

It was indicated that not all levels of anxiety are negative influencer of achievement. Anxiety seems to have little negative effect and may actually improve performance when the given task is relatively simple. However, anxiety will begin to have a negative effect as demands exceed ability (MacIntyre, 1995). In view of the above, it is possible to say that anxiety casts two-dimensional effects on the performance of students.

Based on the findings cited above, excessive anxiety in the foreign language classroom could frequently show up. Thus, reducing the amount of anxiety to the minimum level is found to be important. Evidence (Bekalu, 2010) demonstrates that the learning environment is a potential source in which language anxiety could develop. Bekalu's findings imply that the classroom environment highly influences students' emotional status. That is, the degree of anxiety that students experience could be caused by the learning environment in which students are in. This implies that non-threatening learning environment in language classes is unarguably essential. Abate (1996) also noted that learners learn better in a supportive and non-threatening situation. Worde (2003) stressed that having a relaxed classroom environment is important in reducing anxiety. In a similar study, Horwitz (2001) stated that it might be possible to keep 
anxiety levels to a minimum with a supportive and constructive classroom environment. Thus, anxiety decreases when instructors create a warm social environment (Young, 1999). Students who have supportive learning environment do not feel lonely and they seem to display low anxiety. Students profit a lot from pleasant learning environment. In a pleasant learning environment, students tend to display better emotional stability. This leads students to giant steps forward in exercising proper thoughts. This happens because emotionally supportive environment is influencer of cognitive processing.

This is true since the process of knowledge acquisition or skill development is embedded in the social and emotional context in which learning takes place. Stating the importance of the learning contexts, the cognitive psychologist, Robert Sternberg (1984) cited in Williams \& Burden (1997) argued that we cannot judge the intellectual quality of any behavioral act outside of the context in which it occurs. Sharing the experience of the Hungarian context, Dornyei (2005) underlined that the importance of the classroom climate as a motivational tool was rank ordered second (after the teacher's own behavior) amongst all the motivational dimensions. Driscoll (2005) on his part stated that one of the important characteristics distinguishing Vygotsky's theory from the theories of other developmentalists is his premise that 'individual development cannot be understood without reference to the social milieu in which the individual is embedded'. For Vygotsky, the social factor is felt to be an important factor in educational achievement. The cognitive faculty and the psychological strength or stability of learners are determined by the specific social factor in which they belong. That is why Vygotsky's theoretical framework claims that higher mental processes in the individual have their origin in social processes (Driscoll, 2005).

Key among the issues involved in the learning environment is the quality of interpersonal relation skills students form with teachers. Negative student-teacher interaction is one of those factors that would tend to interfere with the success of learning by eliciting anxiety. Thus, teachers are expected to cultivate the psychological security and feeling of belonging by developing a stress-free environment, by helping students relax, by creating healthy teacherstudent interpersonal behavior, and by promoting self-confidence of students. 


\section{Conclusion and Recommendation}

This study attempts to see the level of language anxiety that freshman students experience. It is also the second objective of this study to look into the effects of anxiety on students' performance. The findings of the study indicate that the independent variable (anxiety) brings effect on the performance of the students. Anxiety and achievement have a form of a curvilinear relationship. Optimal level of anxiety facilitates achievement. But excessive anxiety impedes the performance of students. Excessive anxiety could alienate students from the teaching-learning process. As good feeling adds color to students' classroom behavior, bad feeling makes students disinterested. That is, in addition to the effects that anxiety brings on cognition, anxiety could let students be disengaged from doing classroom tasks. In this regard, students show little investment in their academic task.

Teaching requires interaction and the quality of interaction inevitably embraces more or less or low and excessive anxiety. The nature of interaction should invite less anxiety that motivates students' capacity to learn. Consequently, lessening of anxiety should be a point of teachers' agenda.

Students could slide easily into anxiety due to negative teacher-student interaction, methods of teaching, and the nature of the task given to students to do or due to the newness of the learning environment. Thus, teachers should be more sensitive to conditions that promote feelings of secure. When students are together, they feel more secure. In a collaborative relationship, anxiety is prone to decrease. Furthermore, a conducive learning environment is important for successful learning to take place. This implied that learning environment in which learners try to fit into should be non-threatening. The classroom atmosphere must be an atmosphere of acceptance and mutual respect.

In view of the above points, it is imperative that language teachers develop an awareness of the effects of language anxiety. The study sums up its investigation by suggesting further studies on the area including other institutional and other causal factors which could also be responsible for creating the non-threatening learning environment 


\section{References}

Abate Kassahun (1996). English language classroom anxiety on classroom tasks and in tests: a study of some Ethiopian Civil Service College first year students. Unpublished MA Thesis, Addis Ababa University, Addis Ababa, Ethiopia.

Aida, Y. (1994). Examination of Horwitz, Horwitz, and Cope's construct of foreign language anxiety. The case of students of Japan. The Modern Language Journal, 2(5), 155-167.

Bekalu Atnafu (2006). Demands of the labor market and performance of graduates from the Department of Foreign Languages and Literature in Addis Ababa University. The case of Ministry of Information. Unpublished MA Thesis, Addis Ababa University, Addis Ababa, Ethiopia.

(2010). Psychosocial determinants of anxiety, their relationships and effects in foreign language (English) classes. Unpublished $\mathrm{PhD}$ Dissertation, Addis Ababa University, Addis Ababa, Ethiopia.

Bekele Birhanie (2007). The Relationship between first year English major students preparatory school performance, college entrance exam scores, and their gender and communicative English performance. Bahir Dar University in focus. The Ethiopian Journal of Education, 17(2), 65-90.

Berhanu Bogale (2000). Verbal participation in group work: a case study of first year students at $A A U$. Unpublished $\mathrm{PhD}$ Dissertation, Addis Ababa University, Addis Ababa, Ethiopia.

Brown, H.D. (1994). Principles of Language Teaching and Learning. London: Prentice-Hall International (UK) Limited, $3^{\text {rd }}$ edition

Campbell, C. M. (1999). Language Anxiety in Men and Women: Dealing with Gender Difference in the Language Classroom. In D.J.Young (ed.). Affect in Foreign Language and Second Language Learning: A Practical Guide to Creating a Low Anxiety Classroom Atmosphere (pp.191-215). Boston: MA: Mc Graw-Hill. 
Language Anxiety and Achievement among First Year Students of Addis Ababa University (AAU), Ethiopia

Cheng, Y. (2001). Learners' Beliefs and Second Language Anxiety. National Taiwan Normal University. Retrieved from http://www. Cheng/

Comer, R. J. (2007). Abnormal Psychology: New York. Worth Publisher.

Daly, J. (1991). Understanding Communication Apprehension: An Introduction for Language Educators. In Horwitz, E.K. \& Young, D.C. 1991. Language Anxiety, from Theory and Research to Classroom Implication (pp.3-14). New Jersey, Prentice - Hall, Inc.

Dornyei, Z. (2005). Motivational Strategies in the Language Classroom. Cambridge: Cambridge University Press.

Driscoll, M.P. (2005). Psychology of Learning for Instruction. Boston. Pearson Education, Inc.

Dworetzky, J. P. (1988). Psychology. New York: West Publishing Company

Ellis, R. (1994). The Study of Second Language Acquisition. Oxford: Oxford University Press.

Feigenbaum E. (2007). The Role of Language Anxiety in Teacher-Fronted and Small Group Interaction in Spanish as a Foreign Language: How is pronunciation accuracy affected? University of Pittsburgh: MA Thesis, http://www.feigenbaum/

Finch,A.E. (2001). The Non-threatening Learning Environment. Korea TESOL Journal, 4(1), 133-58.

Foss, R.A \& Reilzel, A.C. (1991). A Relational Model for Managing Second Language Anxiety. In Horwitz, E.K. \& Young, D.C. (Eds). Language Anxiety from Theory and Research to Classroom Implication (pp.129-150). New Jersey: Prentice-Hall, Inc.

Gebeyehu Yismaw (2005). Female Students' English Language Classroom Anxiety in Spoken English Class: A Study of Arbegnoch Senior Secondary School. Unpublished MA Thesis, Addis Ababa University, Addis Ababa, Ethiopia.

Horwitz, E.K. Horwitz. M.B. \& Cope J. (1986). Foreign Language Classroom Anxiety. The Modern Language Journal, 5(70), 125-132.

Horwitz, E.K. (1991). Foreign Language Classroom Anxiety. Language Journal. 5(2), 124-132. 
(2001). Language Anxiety and Achievement. Annual Review of Applied Linguistic. Cambridge: Cambridge University Press.

James, R. (2001). Students' Changing Expectations of Higher Education and the Consequences of Mismatches with the Reality. The University of Melbourne: A Paper for OECDLMHE Conference Management Response to Changing Student Expectations.

Koch, A. \& Terrell, T.D. (1991). Affective Reactions of Foreign Language Students to Natural Approach Activities and Teaching Techniques. In Horwitz E.K. \& Young, D.C. (eds). Language Anxiety from Theory and Research to Classroom Implication (pp.109-125). New Jersey: Prentice-Hall, Inc.

Kondo, D. \& Ying-Ling, Y. (2004). Strategies for coping with language anxiety: The case of students of English in Japan. ELT Journal, 58(3), 258 - 265.

Leki, H. (1999). Techniques for Reducing Second Language Writing Anxiety. In D.J. Young (ed.). Affect in Foreign Language and Second Language Learning: A Practical Guide to Creating a Low Anxiety Classroom Atmosphere (pp.64-88). Boston: MA: Mc Graw-Hill.

MacIntyre, P.D. \& Gardner, R.C (1991). Anxiety and second language learning: Toward a theoretical clarification. In Horwitz, E.K. \& Young, D.C. (Eds.), Language anxiety from theory and research to classroom implication (pp.41-54). New Jersey: Prentice-Hall, Inc.

MacIntyre, P. D. (1995). How Does Anxiety Affect Second Language Learning? A Reply to Sparks and Ganschow. The Modern Language Journal, 79(1), 90-99.

(1999). Language Anxiety: A Review of the Research for Language Teachers. In D.J.Young (Ed.), Affect in foreign language and second language learning: A practical guide to creating a low anxiety classroom atmosphere (pp. 24-46). Boston: Mc GrawHill.

Mekonnen Disasa (1998). Investigating Methods of Training for Developing Student' Skills for Academic Oral Work: Focus on Social Science Students. Unpublished PhD Dissertation, Addis Ababa University, Addis Ababa, Ethiopia. 
Myers, D. G. (2007). Psychology: New York: Worth Publishers.

Ortega Cebreros, A M. (2003). Measuring Language Anxiety Perceived by Spanish University Students of English. Universidad de Jaen: Spain.

Phillips E.A. (1999). Decreasing Language Anxiety: Practical Techniques for Oral Activities. In D.J. Young (Ed.). Affect in Foreign Language and Second Language Learning: A Practical Guide to Creating a low Anxiety Classroom Atmosphere (pp.124-143). Boston: MA: Mc. Graw Hill Companies, Inc.

Price, M.L. (1991). The Subjective Experience of Foreign Language Anxiety: Interviews with Highly Anxious Students. In Horwitz, E.K. \& Young, D.C. (Eds), Language Anxiety from Theory and Research to Classroom Implications (pp.101-107). New Jersey: PrenticeHall, Inc.

Scovel, T. (1991). The Effect of Affect on Foreign Language Learning: A Review of the Anxiety Research. In Horwitz, E.K \& Young, D.C. (Eds). Language Anxiety from Theory and Research to Classroom Implication (pp.15-24). New Jersey: Prentice-Hall, Inc.

Seyoum Tefera (1996). Attempts at Educational Reform in Ethiopia: A Top-down or a Bottomup Reform? The Ethiopian Journal of Education, 16(1), 1-37.

Sileshi Legesse (2001). Making and implementing education policies in Ethiopia since 1974: problems and prospects. Unpublished MA Thesis, Addis Ababa University, Addis Ababa, Ethiopia.

Solomon Moges (2001). An assessment of the relevance of the business English course at Addis Ababa Commercial College to the needs of employing organizations. Unpublished MA Thesis, Addis Ababa University, Addis Ababa, Ethiopia.

Sparks, R.L. \& Ganschow, L. (1999). Native Language Skills, Foreign Language Aptitude, and Anxiety about Foreign Language Learning. In D.J. Young (Ed.). Affect in Foreign Language and Second Language Learning: A Practical Guide to Creating a low Anxiety Classroom Atmosphere (pp.169-190). Boston: MA: Mc. Graw Hill Companies, Inc. 
Tamene Kitila (2000). Classroom verbal behavior and learning opportunities in selected secondary school EFL classroom. Unpublished $\mathrm{PhD}$ Dissertation, Addis Ababa University, Addis Ababa, Ethiopia.

Williams, M. \& Burden, R. (1997). Psychology for Language Teachers: A Social Constructive Approach. Cambridge: Cambridge University Press.

Worde R. (2003). Students' perspectives on foreign language anxiety. Virginian community college system. Retrieved from http//www.vccaedu.org/inquiry/inquiry-spring2003/i81worde.html.

Yalew Endawoke (2003). Causes of Student Attrition in Bahir Dar University: Qualitative and Quantitative Analysis. The Ethiopian Journal of Education, 13(1), 31-66.

Young, D. (1991). The relationship between anxiety and foreign language oral proficiency rating. In Horwitz, E.K. \& Young, D.C. (Eds.), Language anxiety from theory and research to classroom implication (pp.57-64). New Jersey: Prentice-Hall, Inc.

Young, D. (1999). Affect in foreign language and second language learning: A practical guide to creating a low anxiety classroom atmosphere. Boston: Mc Graw-Hill 